\title{
Determining strength of the modified wood
}

\author{
Lesław Kyzioł, Ph.D. \\ Polish Naval Academy in Gdynia
}

\begin{abstract}
The article presents results of investigations of the effect of pinewood modification with methyl polymethacrylate on the anisotropy of its strength in complex stress conditions. The investigations aimed at determining the resistance of the examined wood to stretching, compression, stretching with shear, and compression with shear. For the investigations oriented on shear, shear with stretching, and shear with compression, a special specimen was prepared which differs by notch geometry from a typical Iosipescu specimen. A new test machine is described in the article, which is equipped with special specimen holders to perform investigations in complex stress conditions. Crack patterns recorded for the natural and modified wood are presented. For all tests, numerical FEM simulations were performed to obtain stress distributions inside the specimens. The calculated stress distributions were visualised as contour line projections for the natural and modified wood.
\end{abstract}

Keywords: wood modification, wood-polymer composite, Iosipescu specimen, stress distribution in the specimen under load.

\section{INTRODUCTION}

Numerous authors $[5,6,10,11]$ claim that the properties of the modified wood relating to its strength and deformation increase or decrease in proportion to the amount of the modifying substance.

All changes of mechanical properties of the wood exposed to the modification cannot be fully predicted without relevant experimental tests.

The goal of the reported activities was to determine the effect of pine whitewood modification of its strength anisotropy in complex stress conditions.

Wood is an orthotropic material revealing remarkably different strength characteristics depending on the anatomic direction. The literature makes distinction between three wood directions: longitudinal, tangential, and radial. The adopted

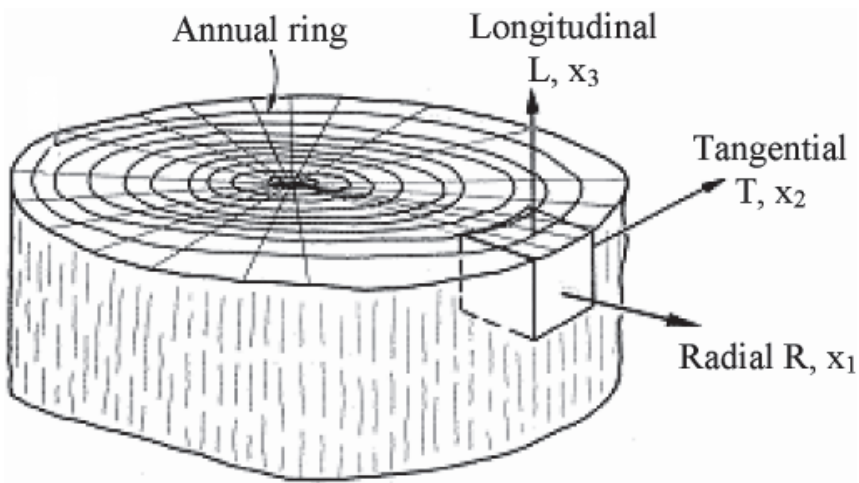

Fig. 1. Orientation of anatomic directions of the wood in rectangular coordinate system coordinate system is shown in Fig. 1 - the L axis is in the anatomic direction along the fibres, the $\mathrm{R}$ axis is in the radial direction, and the $\mathrm{T}$ axis is directed tangentially to the surfaces of particular fibre layers.

\section{COURSE OF INVESTIGATIONS}

In order to examine the effort of the examined materials, tests were performed to determine wood resistance to stretching, compression, stretching with shear, and compression with shear. The shapes and dimensions of the specimens used for tests were taken from relevant standards $[22 \div 25]$.

The specimens were formed from a wooden square timber, seasoned in natural conditions in the temperature of $295 \pm 2 \mathrm{~K}$. The average humidity of the specimens was equal to $8 \%$. The tests were performed on natural wood specimens and those exposed to the modification process. The modification consisted in saturating the wood with the hydroquinone methyl ether modified methacrylate (MM), with further thermal polymerisation. The degree of specimen saturation with the monomer was controlled by adjusting the time during which the specimen was in the autoclave, in the way described in [21]. The modified wood with different contents of methyl polymethacrylate was marked, respectively, as $\mathrm{K} 0.0$, K0.35, $\mathrm{K} 0.43$, K0.48 and $\mathrm{K} 0.56$, where the numbers represent the number of kilograms of methyl polymethacrylate with respect to $1 \mathrm{~kg}$ of dry wood.

The stretching and compression tests were done on a universal test machine MTS-810.12, while the shear tests were performed on a machine designed and produced especially for 
this purpose [21]. Wood resistance to stretching, compression, and shear was determined based on the arithmetic mean of 6 to 10 specimens. The mean values and the statistic processing are discussed in [21]. The results of the mean value analysis are given in Table 1.

Tab. 1. Resistance limits to stretching, compression, and shear of natural and modified wood

\begin{tabular}{|c|c|c|c|c|c|}
\hline $\begin{array}{c}\text { Type of } \\
\text { material }\end{array}$ & $\begin{array}{c}\mathbf{R}_{\mathbf{m}_{I I}} \\
{[\mathbf{M P a}]}\end{array}$ & $\begin{array}{c}\mathbf{R}_{\mathbf{c}_{I I}} \\
{[\mathbf{M P a}]}\end{array}$ & $\begin{array}{c}\mathbf{R}_{\mathbf{m}_{\perp}} \\
{[\mathbf{M P a}]}\end{array}$ & $\begin{array}{c}\mathbf{R}_{\mathbf{c}_{\perp}} \\
{[\mathbf{M P a}]}\end{array}$ & $\begin{array}{c}\mathbf{R}_{\mathbf{t}} \\
{[\mathbf{M P a}]}\end{array}$ \\
\hline $\mathrm{K} 0.0$ & 95 & 55 & 4.5 & 8.5 & 22.10 \\
$\mathrm{~K} 0.35$ & 102 & 70 & 7 & 24 & 25.68 \\
$\mathrm{~K} 0.43$ & 110 & 80 & 8 & 26 & 26.50 \\
$\mathrm{~K} 0.48$ & 112 & 88 & 8.5 & 29 & 27.80 \\
$\mathrm{~K} 0.56$ & 118 & 98 & 9 & 32 & 30.20 \\
\hline
\end{tabular}

where: $\mathrm{R}_{\mathrm{m}_{\mathrm{II}}}$ - resistance to stretching along fibres; $\mathrm{R}_{\mathrm{c}_{\mathrm{II}}}$ - resistance to compression along fibres; $\mathrm{R}_{\mathrm{m}_{\perp}}$ - resistance to stretching across fibres; $\mathrm{R}_{\mathrm{c}_{\perp}}$ - resistance to compression across fibres; $\mathrm{R}_{\mathrm{t}}$ - shear resistance

\section{RESISTANCE OF THE MODIFIED WOOD TO IN-PLANE SHEAR}

Prognosing strength of such composite layer structures as the wood is of vital importance in designs making use of this material. An important parameter which should be known in wood-based designs is wood resistance to in-plane shear. The literature sometimes gives contradictory data on the levels of wood resistance, which is not surprising [15]. The absence of reliable methods measuring material's resistance to in-plane shear results in little confidence in official design limitations, a consequence of which is taking into account excessive margins in design activities involving in-plane shear strength.

Methods of composite resistance investigations can be divided into tests making use of tubular specimens and plane specimens. Preparing wooden tubular specimens for investigations in complex load conditions is difficult due to the anatomic structure of the wood (annual rings), therefore in the reported case a decision was made to perform tests using plane specimens.

So far, a specimen which was found to be most useful, due to its shape, for composite tests is the Iosipescu specimen [4, $8,9]$. Attempts to adapt it to testing composites in plane stress conditions, following the method based on the Arcan instrument [4], were initiated by Broughton [7]. Its applicability for shear tests of various layer composites was confirmed by numerous investigation reports $[1,2,13,17 \div 19]$.

The failure of the Iosipescu specimen can be reached in the uniform stress conditions, although the presence of undesired transverse stress makes the interpretation of the shear resistance more complicated.

Below, assumptions are presented which refer to the measurement of the shear resistance of the composite Iosipescu specimens in the test bearing the name of the V method (ASTM D5379M:93). The definition of the shear resistance is, generally, not clear [14,21]. For instance, for the same material Broughton [7] says about the "failure stress" equal to $58 \mathrm{MPa}$, while Morton [12] says about the "shear resistance" equal to $68 \mathrm{MPa}$. At the same time Adams [1] says about the "shear resistance" equal to $115 \mathrm{MPa}$ for the same material and specimen, but another definition of the failure point $[14,15,21]$.

When testing plane specimens we have to take into account that reaching the failure criterion generates the necessity for the appearance of shear. An important feature of the test is stress uniformity in the examined specimen area.

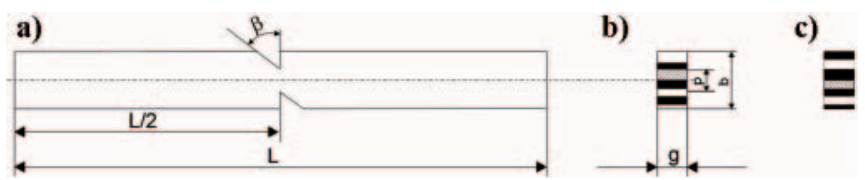

Fig.2.: a) modified Iosipescu specimen, b) specimen with summer wood upper layers, c) specimen with spring wood upper layers. $\beta=45^{\circ}, g=5$ $\mathrm{mm}$ - specimen thickness, $b=20 \mathrm{~mm}$-specimen width, $p=5 \mathrm{~mm}$-length of measuring section, $L=80 \mathrm{~mm}$-specimen length

Preliminary tests performed on a typical Iosipescu specimen (with an alternate system of layers, not always parallel to each other, sometimes twisted) have revealed that correct results cannot be obtained. During shear tests of this piece, it is not only the shearing stresses which are observed at the bottom of the notch. When the specimens are loaded with transverse load, their bending is observed, with the resultant normal stress generated by the bending moment. The wooden fibres are deformed (bent and stretched). Recognising the beginning of specimen failure is difficult [21].

Taking into account the experience gained by Iosipescu [8], a specimen was prepared which was then tested many times to reach the final shape and dimensions shown in Fig. 2. This specimen differs considerably from the typical Iosipescu piece by the notch geometry. Adopting such a specimen geometry is a result of long lasting experiments, numerical calculations and observations recorded during the tests. The depth of the notch with respect to the thickness of layers was selected in such a way that the beginning of the notch is at its edge [21].

The examined specimens had various configurations of softwood and hardwood layers. When preparing the specimens, care was taken that the wood layers were situated parallel to each other and had constant thickness along the specimen length.

There are test machines, produced in series, which are equipped with special holders for performing investigations in complex load conditions. However, due to high costs of these machines and specific nature of investigations, similar machines are frequently designed and produced individually in laboratories in which the investigations are preformed.

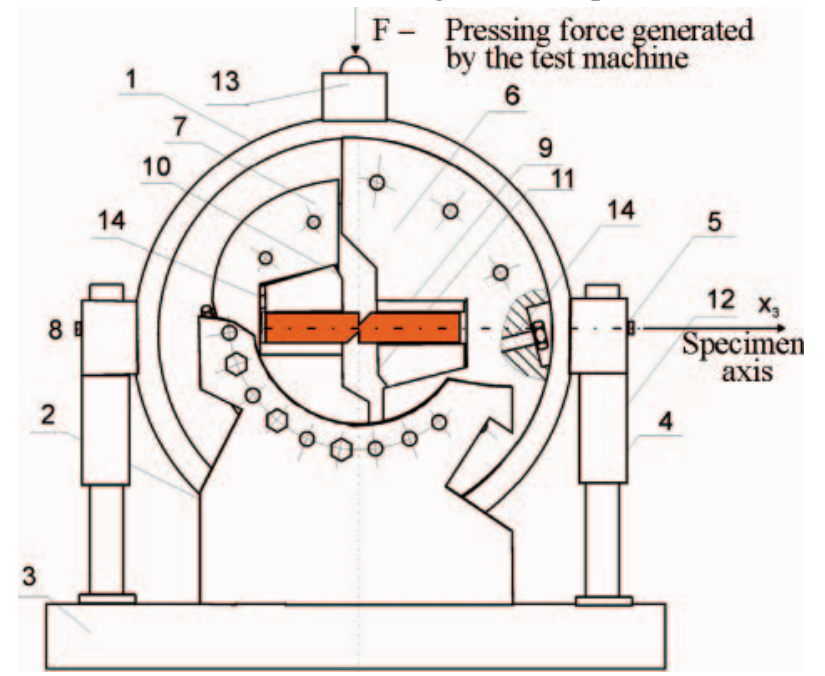

Fig. 3. Machine for generating plane stress distribution:

$\mathbf{1}$ - casing; $\mathbf{2}$ - console; $\mathbf{3}$ - base; $\mathbf{4}$ - guide; $\mathbf{5}$ - pilot sleeve; $\mathbf{6}$ - right holder; 7 - left holder; $\boldsymbol{8}$ - insert for left holder jaw; 9 - insert for right holder jaw; 10 - left locking block; 11 - right locking block; 12 - guide sleeve; 13 - $\varphi 12$ ball and ball fixing; 14 - M6 bolt.

The designed and produced machine [21], shown in Fig. 3, has made it possible to generate the plane stress distribution, Fig. 2. Compared to a traditional test machine [7, 20], the position of the specimen axis with respect to the direction of 
force $F$ can be changed. As a result, depending on the specimen position angle with respect to the load direction, stretching or compression can be executed along with shear in the central part of the specimen.

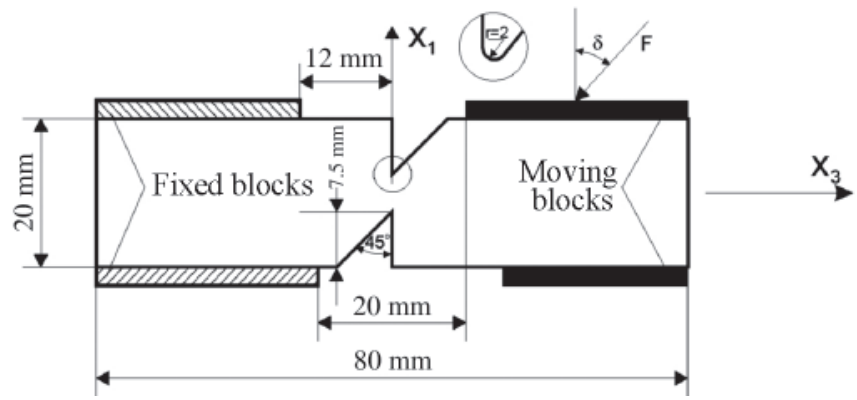

Fig. 4. Scheme of kinetic load of the specimen

The moving and fixed blocks are preliminary clamped in such a way that the $\mathrm{Fx}_{3}$ component of force $\mathrm{F}$ is smaller than the friction force between the blocks and the specimen. However, this clamping generates a preliminary stress. Taking this into account, the clamping force was selected experimentally at a level securing fulfilment of its function and, at the same time, not affecting considerably specimen's strength. Then the moving blocks were moved in the direction inclined at the angle $\delta$ to the specimen axis. During the tests the value of force $\mathrm{F}$ was measured in relation to specimen displacement. When $\delta=0$, the stress is close to pure shear. The test machine makes it possible to change the angle within the range $-45 \div 45^{\circ}$. Specimen stretching and compression in the direction of the $\mathrm{x}_{3}$ axis was done when the specimen was mounted directly in the machine jaws.

The scheme shown in Fig. 4 reveals some displacements of the upper blocks with respect to their lower counterparts. The scale of this displacement was set experimentally. It was large enough to generate united displacements at the contacting edges between the blocks and the specimen, which was of high significance for the operation of the FEM model used for the numerical stress analysis.

For $\delta=0$, shear of the specimen is observed as provoked by the applied vertical displacement $U_{x}$, Fig. 4. The machine that loads the specimen records, via a relevant measuring instrument, the force along with the corresponding displacement. During specimen shear, the displacement $U$ of the machine right-hand side, corresponding to force $F=F_{t}$, is directed along the $\mathrm{x}_{1}$ axis. For negative (counterclockwise) specimen rotation angles in the test machine, see Fig. 3, force $\mathrm{F}$ generates shear $\mathrm{F}_{t}$ and compression $\mathrm{F}_{\mathrm{c}}$ within the specimen, while for positive (clockwise) angles force $\mathrm{F}$ generates shear $\mathrm{F}_{\mathrm{t}}$ and stretching $\mathrm{F}_{\mathrm{m}}$.

Fig. 5 shows a sample relation between the loads of the specimens made of natural and modified wood, and the holder displacements for $\delta=0^{\circ}$. Numbers $1 \div 4$ denote successive crack stages of the specimen made of natural wood. The specimen failure does not take place immediately after the appearance of the first crack, as the arrangement of the wood layers with respect to the direction of force action changes at that moment. Further increase of load generates next cracks.

Some authors suggest that the final crack takes place, for plastics, in the uniform shear conditions. Unfortunately, no investigations were performed to verify this thesis $[3,7,16]$. Other authors propose to interpret the shear stress recorded at the appearance of final crack as the shear resistance.

Here, for both the natural and modified wood the shear resistance was assumed as that observed at the first crack of the specimen, Fig. 5 [21].

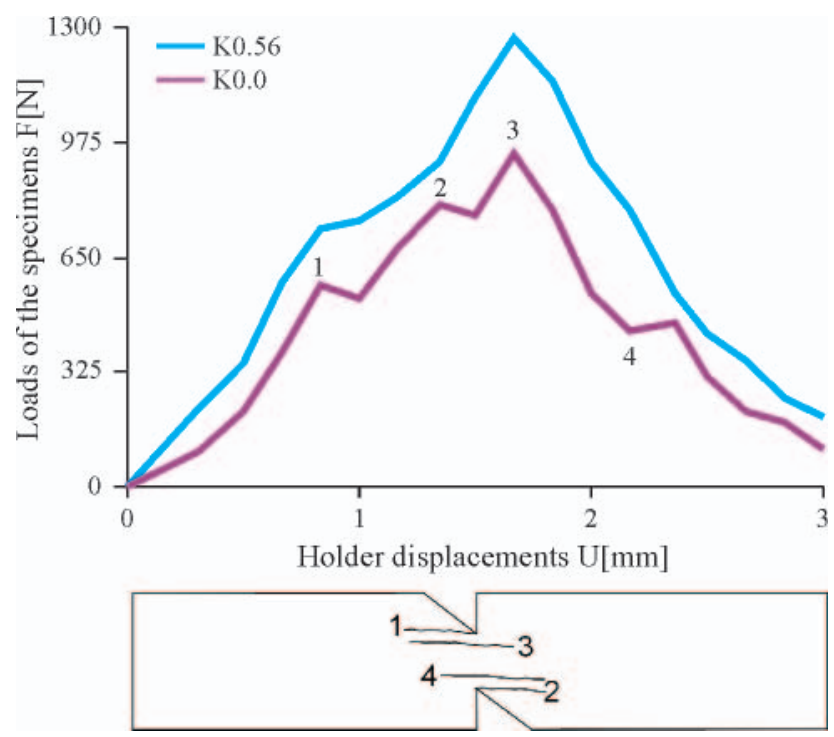

Fig. 5. Load-displacement curve with characteristic points of crack beginning (1,2, 3, 4-successive stages of specimen crack)

Fig. 6 shows crack patterns observed for the natural and modified wood. When exposed to load, the layers of the natural wood resembled significantly deformed "threads", and recording the time when the last layer is damaged was
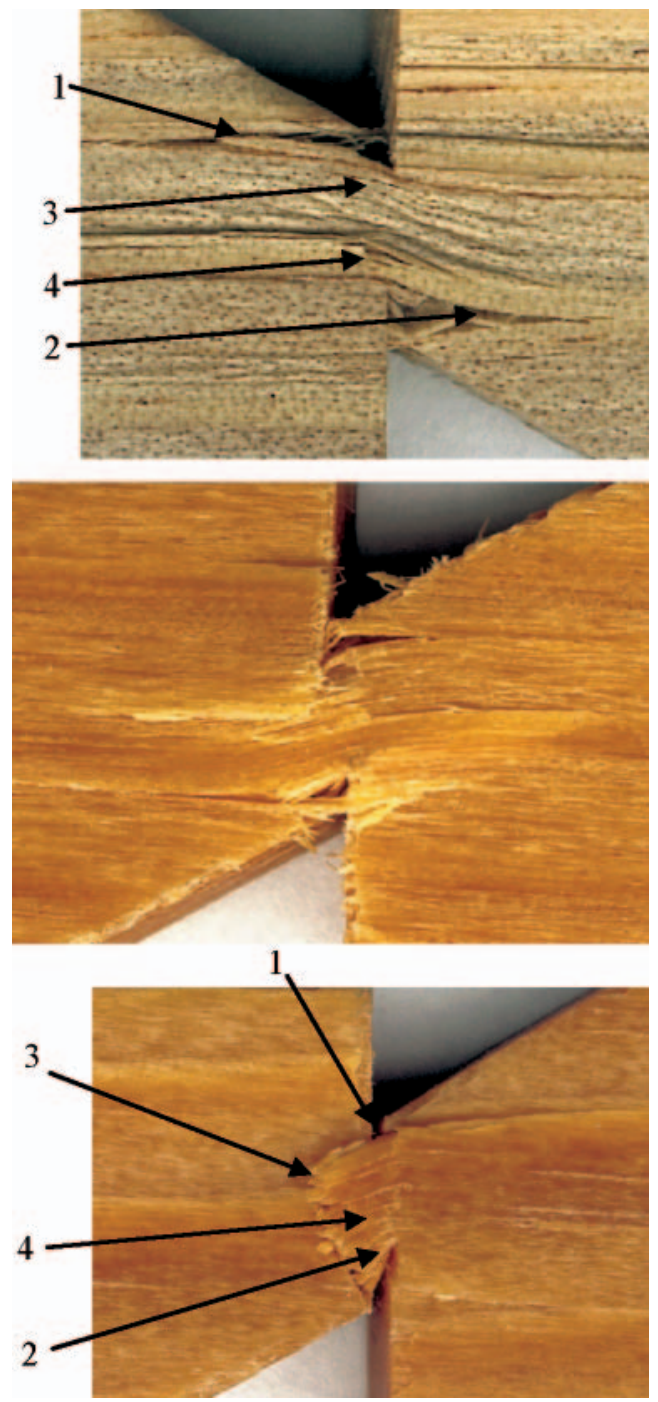

Fig. 6. Specimen crack patterns: a) natural wood, b) composite $D-P M M K 0.35$, c) composite D-PMM K0.56

(1, 2, 3, 4-successive stages of wooden specimen crack) 
difficult. Specimens of the modified wood revealed higher crack resistance. When the content of the polymer in the composite was higher, the material became more resistant to failure, Figs. 5 and $6 \mathrm{c}$. The nature of crack of the modified wood K0.35 resembled an intermediate crack pattern between that observed for brittle and ductile material.

The above course of specimen crack referred to the case of shear. In a similar way, depending on the selected angle of specimen axis with respect to the direction of load, forces $F$ were recorded assuming that the specimen resistance corresponds to the first crack (point 1 in Fig. 5). By changing the specimen position angle by $15^{\circ}$ within the range $-45 \div 45^{\circ}$ the relation was obtained between the force $\mathrm{F}$ corresponding to the first crack and the angle $\delta$.

Fig. 7 shows loads of specimens made of natural and modified wood in relation to the angle $\delta$ until the appearance of the first crack.

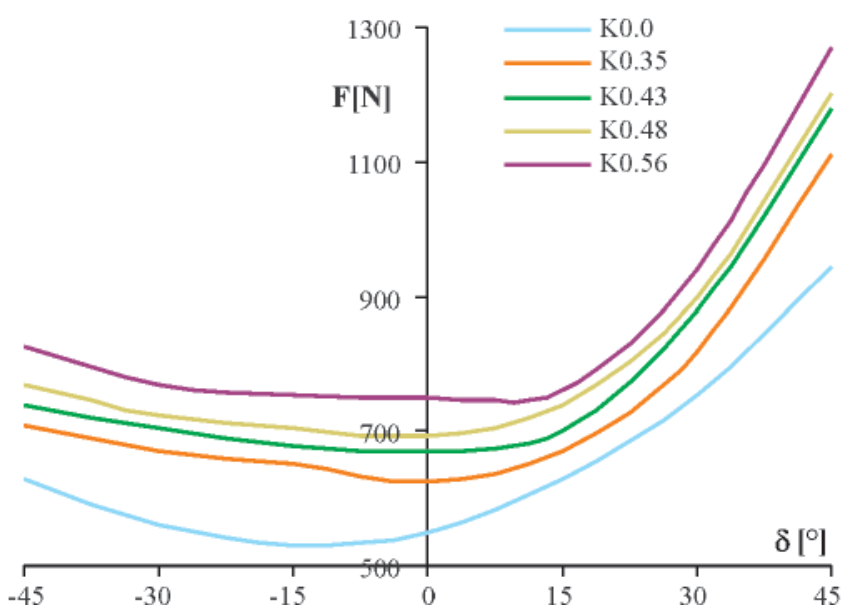

Fig. 7. Dependence of specimen load on the angle $\delta$ until the appearance of the first crack $\delta$ - specimen rotation angle with respect to the horizontal position

\section{ANALYSING TEST RESULTS}

For all tests, FEM-based numerical simulations were performed to obtain stress distributions inside the pieces. In the calculation model the plane stress was assumed, and the discretisation was done in such a way that each layer of the soft and hard wood was modelled in the perpendicular direction by two nine-node elements. Physical properties of particular layers were described using a generalised Hooke law for orthotropic materials. Based on the obtained results, the flexibility matrices were determined for the soft and hard layers of the natural wood K0.0 and the modified wood K0.56 [21].

On average, the specimen consisted of seven softwood layers and eight hardwood layers, or the opposite. The ratio between the thicknesses of hardwood layers to softwood layers was approximately equal to 0.5 . The depth of the notch with respect to the layers was selected in such a way that the beginning of the notch was at the edge of the layer and not in the middle of it. The layers were assumed to be situated parallel to each other and have constant thickness along specimen length. In the measuring section the top layer can be the either softwood or hardwood layer, Figs. 2b, c).

The specimen load was executed by moving the edges which were in contact with the moving blocks in the direction inclined by $\delta$ to the specimen axis. When the force calculated from stresses for section $\mathrm{x}_{3}=0$ was equal to that measured, the obtained stress conditions were assumed as corresponding to specimen failure. Comparing edge displacements assumed in the calculations with the measured values made the basis for verification of the calculation model.

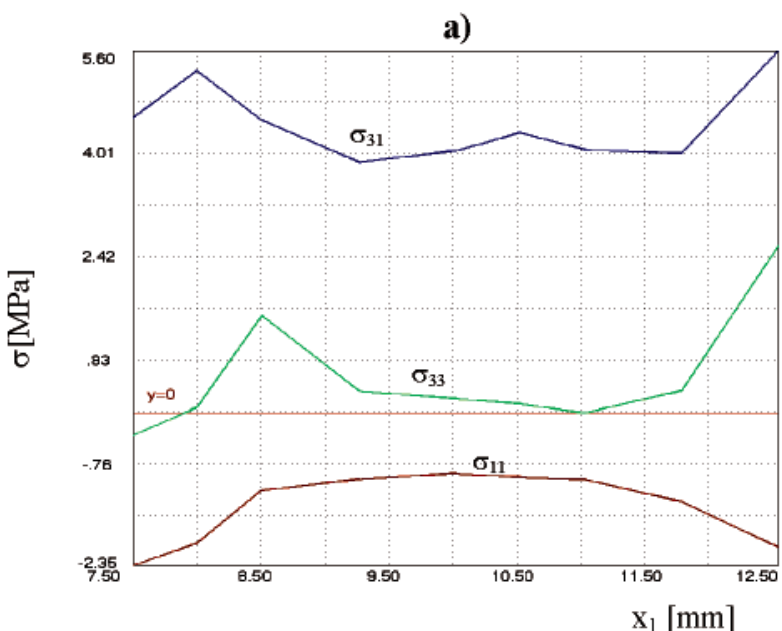

b)

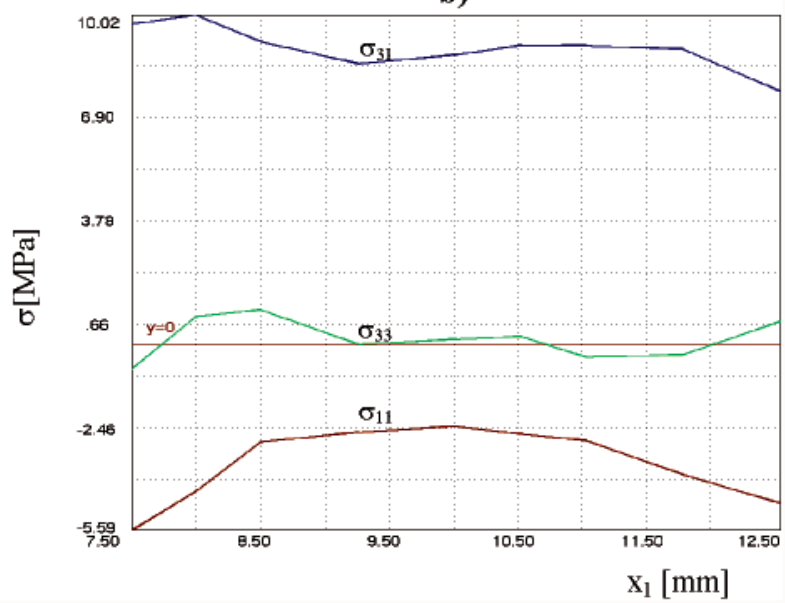

Fig. 8. Distribution of stresses in the measuring sections of the specimens made of: a) natural wood KO.O, b) modified wood K0.56 exposed to complex stress conditions for $\delta=0^{\circ}$

Fig. 8 presents stress distributions in the measuring sections of the specimens made of natural wood K0.0 and modified wood $\mathrm{K} 0.56$ for $\delta=0$. Here, the shearing stresses $\sigma_{31}$ take the highest values, while $\sigma_{33}$ and $\sigma_{11}=0.25 \sigma_{31}$ are close to zero. The stress distributions along the examined measuring sections of the specimens made of natural and modified wood differ between each other. For the natural wood, the saw-like shape of the diagram suggests the appearance of increased stresses in the hardwood with respect to those observed in the softwood. In the modified wood, on the other hand, the stress distribution is close to uniform, as elastic properties of the layers are similar to each other. Modifying the soft layers led to the "homogenisation" of the material, as a result of which the stress distribution curve is more uniform.

Figs 9 and 10 show, in the form of contour lines, the distributions of stress $\sigma_{31}$ calculated using the FEM method for $\delta=0$ for natural and modified wood, respectively. The distribution of the tangential stress in the measuring section of the specimen made of natural wood, Fig. 9, reveals much higher effort of the hardwood than that of the softwood. Moreover, within the entire measuring section the material effort is more than twice as high as in the corresponding section of the modified wood, see Fig. 10. This effect is believed to have been caused by the "homogenisation" of the material in the hardwood layer direction [21].

For the specimen made of natural wood, stress distributions in the analysed section are shown Figs. 11a and b, while for the modified wood - in Figs. 11c and d. As can be noticed, the stresses for the two angles differ not only by a sign, but 
also by an absolute value. These differences are much higher for the natural wood than for the modified wood. Similar differences in stress distributions in the measuring sections of the specimens made of wood K0.0 and K0.56 were recorded at complex load conditions for $\delta=90$ and $\delta=-90$. In the specimens exposed to load for $\delta=90$ and $\delta=-90^{\circ}$ the dominating stresses $\sigma_{33}$ are accompanied by limited stresses $\sigma_{33}$ and negligible shear stresses. For the both cases $(\delta=90$ and $\delta=-90^{\circ}$ ) the tests were performed on a universal test machine MTS 810.12.

The shear resistances and stress distributions were determined in complex load conditions (shear with stretching, and shear with compression) in the measuring sections of the specimens made of natural and modified wood. If the top layer in the measuring section was the hardwood layer, the stresses were higher than in case when the softwood layer was the top layer.

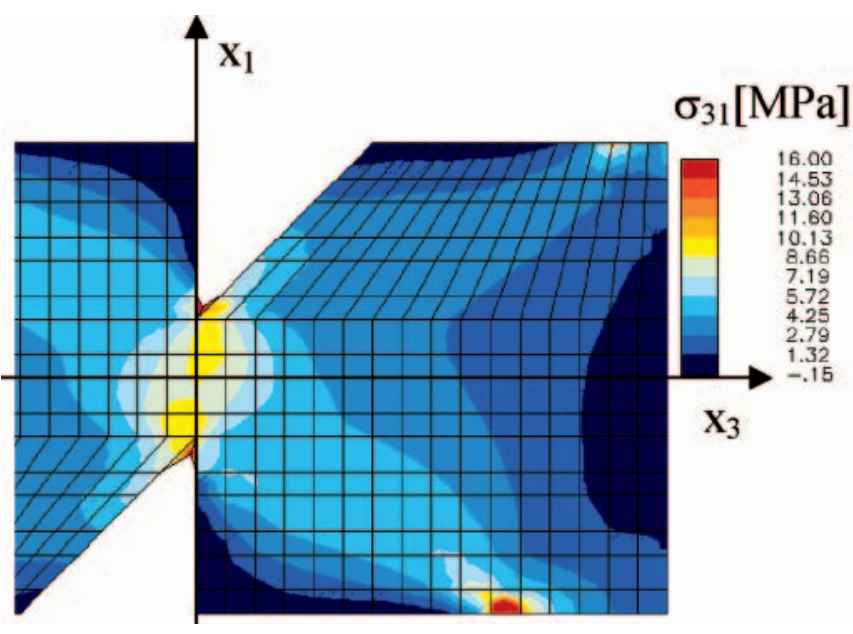

Fig. 9. Distribution of $\sigma_{31}$ stress in selected natural wood specimen area

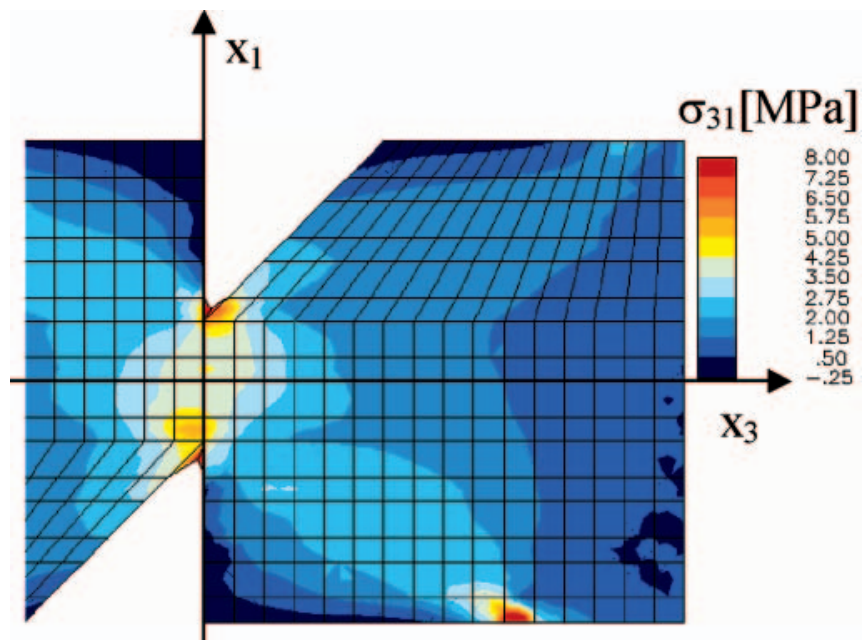

Fig. 10. Distribution of $\sigma_{31}$ stress in selected modified wood specimen area a)

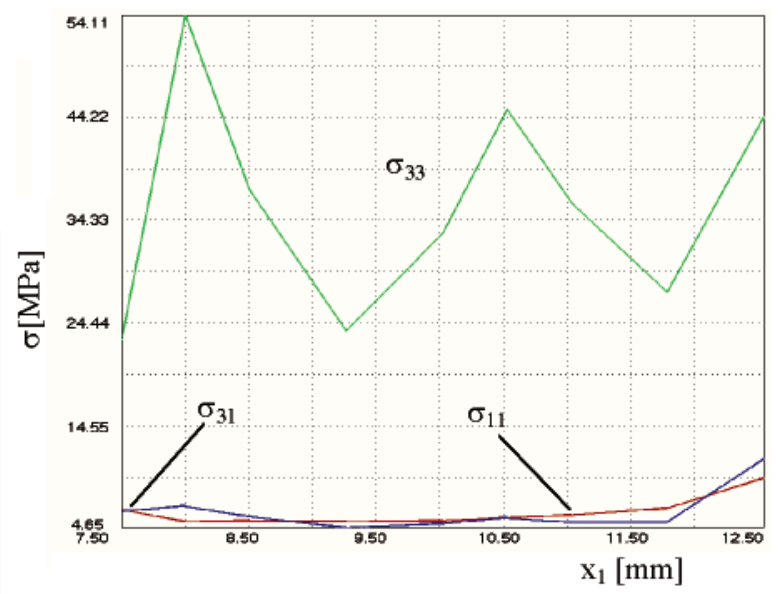

b)

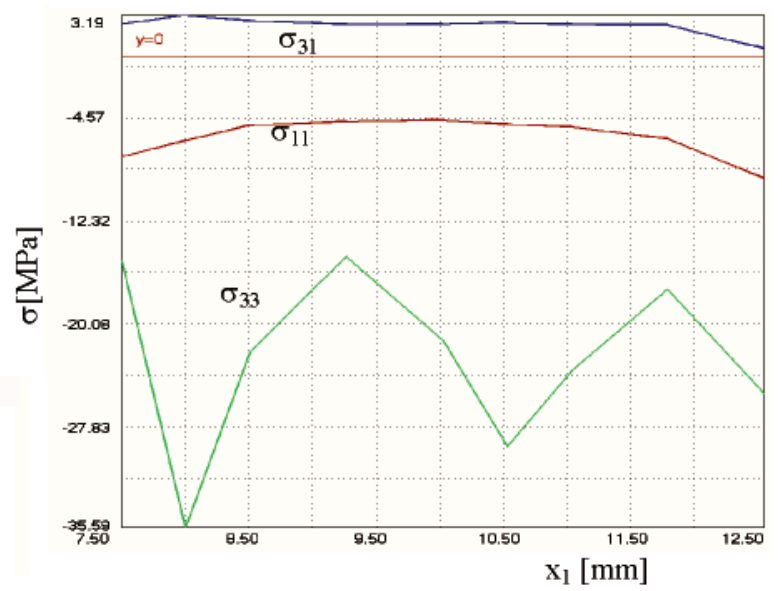

c)

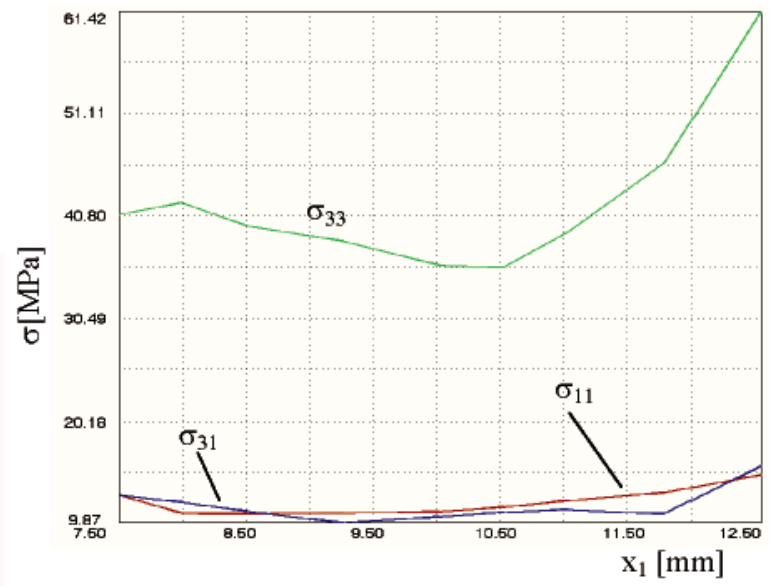

d)

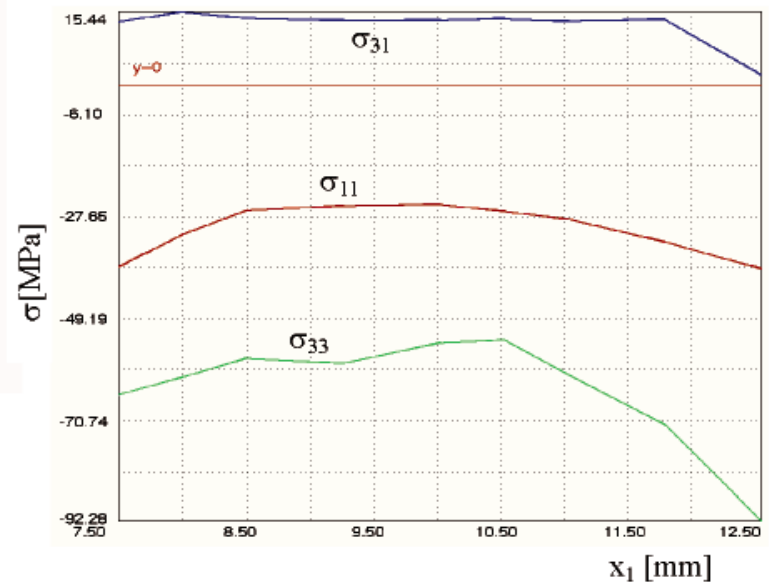

Fig. 11. Distribution of stresses in the measuring sections of specimens made of natural wood K0.0 at complex stress conditions for: a) $\delta=45^{\circ}$, b) $\delta=-45^{\circ}$ and modified wood $K 0.56$ for: c) $\delta=45^{\circ}$, d) $\delta=-45^{\circ}$ 


\section{FINAL CONCLUSIONS}

The performed tests have made it possible to formulate the following conclusions:

When being compressed along the fibres, the effort of the modified wood can be nearly twice as high as for the natural wood. In case of compression across the fibres this ratio is even higher and can exceed 4. Also during stretching, remarkable increase of strength of the modified wood is observed.

Stress distributions in specimens made of natural and modified wood and exposed to load reveal differences in levels and shapes. These differences are much higher for natural wood.

When exposed to load, layers of the natural wood resembled significantly deformed "threads" and capturing the time when the last layer was damaged was difficult. The specimens made of modified wood revealed higher crack resistance. Increasing the content of polymer resulted in "homogenisation" of the wood structure, as a result of which the material became more resistant to failure.

In the elements made of natural wood remarkable differences in the efforts of soft and layers were observed, while in the superficially modified wood the efforts of the soft and hard layers situated close to the surface were almost the same.

In case of bent or twisted elements, a sufficient approach is to modify the wood only superficially. The softwood layers are strengthened and take over some part of the load from the hardwood layers. This way the stress distribution becomes more uniform.

\section{BIBLIOGRAPHY}

1. Adams D.F., Lewis E.Q.: Experimental strain analysis of the Iosipescu shear test specimen. Exp. Mech., Vol. 35, No. 2, pp. 352-360, 1997

2. Adams D.F., Lewis E.Q.: Experimental assessment of four composite material shear test methods. J. Test. Evaluat. Vol. 25, No. 2, pp. 242-254, 1995

3. Adams D.F., Walrath D.F.: Current status of the Iosipescu shear test, J. Comp. Mat., Vol. 25,No. 1, pp. 494-506, 1987

4. Arcan M., Hashin Z., Voloshin A.: A method to produce uniform plane-stress states with applications fiber-reinforced materials. Exp. Mech., Vol. 18, pp. 141-145, 1984

5. Boding J., Goodman I.R.: Prediction of elastic parameters for wood, Wood Sci., Vol.5, No. 4, pp. 378-385, 1973

6. Boding J., Jayne B., A.: Mechanics of wood and wood composites, Van Nostrand Reinhold, New York, 1982

7. Broughton W.R., Kumosa M., Hill D.: Analysis of the Iosipescu shear test applied to unidirectional carbon-fiber reinforced composites, Comp. Science Tech., Vol. 38, pp. 299-325, 1990

8. Iosipescu N.: New accurate procedure for single shear testing of metals. J. Mater., Vol. 2, No. 3, pp. 537-566, 1967
9. Kumosa M., Hull D.: Mixed - mode fracture of composites using Iosipescu shear test. Int. J. Fracture, Vol. 35, pp. 83-102, 1987

10.Kyzioł L.: Modified wood - a promising material for shipbuilding. Polish Maritime Research, pp. 6-10, 1999

11.Kyziol L, Kowalski S. J.: Mechanical Properties of Modified Wood-IUTAM Symposium on Theoretical and Numerical Methods in Continuum Mechanics of Porous Materials. University of Stuttgart, Germany, September 5-10, pp.221-229, 1999

12.Morton J., Ho H., Tsai M. Y., Farley G.: An evaluation of the Iosipescu specimen for composite materials shear property measurement. J. Compos. Mater., Vol. 26, pp. 708-750, 1992

13.Ochelski S.: Critical evaluation of selected methods of composite investigations (in Polish). WAT Bulletin, Year XLIX, No. 7, pp. 23-33, 2000

14.Pierron F., Vautrin A.: Analyse de la rupture d'éprouvettes Iosipescu: application à la mesure de la résistance au cisaillement. Ninth French Conference on Composite Materials, Vol.2, Saint-Etienne, 22-24 November, pp. 709-718, 1994

15.Pierron F., Vautrin A.: Measurement of the in-plane shear strengths of unidirectional composites with the Iosipescu test. Composites Science and Technology, Vol. 57, pp. 1653-1660, 1997

16.Pindera M.J. et all.: A methodology for accurate shear characterization of unidirectional composites. J. Compos. Mater., Vol. 21, pp. 1164-1185, 1987

17.Swanson S.R., Messick M., Tombes G.R.: Comparison of torsion tube and Iosipescu in-plane shear test results for a carbon fibre reinforced epoxy composite. Composites, Vol. 16, No. 3, pp. 178-183, 1985

18.Tarnopolskij Yu. M., Arnautov A.K., Kulkov V.L.: Methods of determination of shear properties of textile composites. Composites Part A, Vol. 30, pp. 879-885, 1999

19. Walrath D.E., Adams D.F.: The Iosipescu shear test as applied to composite materials. Ex. Mech. Vol.3, pp. 105-110, 1983

20.Wang Ch.H., Chalkley P.: Plastic yielding of film adhesive under multiaxial stresses. Inter. J. Adhesion Adhesives, Vol 20, pp. 155-164, 2000

21.Kyzioł L.: Analysing properties of the constructional wood superficially saturated with the MM polymer (in Polish), Polish Naval Academy in Gdynia, No. 156 A, 2004

22.PN-79/D-04229. Wood. Determining resistance to compression across fibres (in Polish)

23.PN-81/D-04108. Wood. Determining resistance to stretching across fibres (in Polish)

24.PN-81/D-04107. Wood. Determining resistance to stretching along fibres (in Polish)

25.PN-79/D-04102. Wood. Determining resistance to compression along fibres (in Polish).

\section{CONTACT WITH THE AUTHOR}

Lesław Kyzioł, Ph.D.

Faculty of Mechanical and Electrical Engineering Institute of Basic Engineering

Polish Naval Academy in Gdynia Śmidowicza 69

81-103 Gdynia, POLAND

e-mail: L.Kyziol@amw.gdynia.pl 